\title{
Review Paper: The Effect of Splinting After Dupuytren's Contracture Operation: A Systematic Review
}

\author{
Marzieh Pashmdarfard $^{1}$ (i), Akram Azad ${ }^{1 *}$ (i), Malek Amini' ${ }^{1}$, Ghazale Golabi $^{1}$ (D) \\ 1. Rehabilitation Research Center, Department of Occupational Therapy, School of Rehabilitation Sciences, Iran University of Medical Sciences, \\ Tehran, Iran.
}

\begin{tabular}{c|l}
$\begin{array}{c}\text { Use your device to scan } \\
\text { and read the article online }\end{array}$ \\
Crtation: Pashmdarfard M, Azad A, Amin M, Golabi Gh. The Effect of Splinting After Dupuytren's Contracture Operation: A \\
Systematic Review. Iranian Rehabilitation Journal. 2019; 17(4):297-304. http://dx.doi.org/10.32598/irj.17.4.297 \\
dol'http://dx.doi.org/10.32598/irj.17.4.297
\end{tabular}

(c) (i) (\$)

Article info:

Received: 10 June 2019

Accepted: 12 Aug 2019

Available Online: 01 Dec 2019

\section{Keywords:}

Dupuytren's contracture, Hand therapy, Occupational therapy, Splints, Operative

\section{ABSTRACT}

Objectives: Flexion contracture in fingers of hands is a complication of Dupuytren's contracture and cannot be stopped by the progressive course. The aim of this study was to review the effect of splinting in the correction of contracture after Dupuytren's contracture operation.

Methods: To carry out this research, a kind of systematic evidence-based review process (Duffy 2005) was used. For data gathering, we used electronic database and Persian- and English-language specific journals between 1990 and January 2019. The keywords were related to examine the effect of various splinting after Dupuytren's contracture operation.

Results: After data gathering, 26 articles about Dupuytren's contracture were found; after checking and deep reviewing of those articles, 17 articles were removed from the study and 9 articles were included in the study for reviewing. The results of a review article based on using splint in Dupuytren's contracture after operation were classified into 6 categories, including static splint, dynamic splint, day splint, night splint, the time duration of splinting, and prescribed time of splinting.

Discussion: Splint alone has been ineffective in reducing contracture. Static splint and hand therapy (exercise) are together the most effective way for the treatment of Dupuytren's contracture. Occasional and irregular use of splint also has no effect on pain relief and the reduction of contracture. The pressure and force of splint will be gradually increased, and the splint should be used at least for 3 months, too.

\section{* Corresponding Author: \\ Akram Azad, PhD.}

Address: Rehabilitation Research Center, Department of Occupational Therapy, School of Rehabilitation Sciences, Iran University of Medical Sciences, Tehran, Iran.

E-mail:azad.a@iums.ac.ir 


\section{Highlights}

- The most effective way for the treatment of Dupuytren's contracture is to use splint after the operation.

- Exercise with the splinting effect is ineffective in reducing the contracture.

- Night static splints are effective in improving the range of motion and performance of their hands of Dupuytren's contracture.

\section{Plain Language Summary}

Dupuytren's contracture is a controversial problem with orthopedics and rehabilitation. It is commonly used in surgical procedures, splint administration, and rehabilitation exercises. Considering the experience and studies of rehabilitation specialists, simultaneously, these methods have a more favorable outcome in improving hand function. Surgical technique, type of exercise, and how to use the splint are very important. According to the results of this study, splinting with postoperative exercises was more effective in surgical outcomes. Of course, the duration of using the splint, how to use it overnight or daily, and the length of use of the splint for better treatment results should be addressed to therapists.

\section{Introduction}

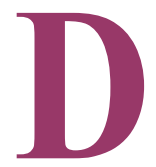

upuytren's Contracture (DC) or Dupuytren's Disease is a kind of active and benign cell proliferation in the palmar facial tissue that can lead to disability [1]. It develops in middle age and creates a progressive flexor contracture in the hands, especially along with the index and little fingers. Palter (1614) was the first expert to explain the disease that it was a type of disorder in palm facial was read by hard-working people. In 1831, Guillaume Dupuytren's expanded the previous approach, and he described the disease as cellular proliferation. This proliferation results in the formation of a nodule in the palm of the hand, and palmar fascia becomes rope-shaped and this is what leads to the creation of flexor contracture on the joints of the fingers.

Flexion contracture is a natural part of this disorder and cannot be stopped by the progressive course. The underlying cause of this disorder is still unknown, but the factors that may be lead to this disorder include genetic factors, race, gender (in men 8-9 times more likely than women), cancer, epilepsy, thyroid disorders, AIDS, alcohol, and smoking [2]. Therefore, we cannot slow down the course of this disease, and no conservative treatments such as splinting can delay progress. The main treatment is operation (fasciotomy, Zplasty, skin graft), which is raised after that the need for rehabilitation. The surgical criterion is the presence of 35-degree flexion contracture in metacarpophalangeal and proximal interphalangeal joints [1-3]. Since the operation leads to scar formation, the temporary limitation of hand functions in order to carry out activities of daily living and occupation, sen- sory problems, edema, and abnormalities in blood circulation to surrounding tissues.

Occupational therapy can be used for hand rehabilitation after assessments in the field of skin and ulcer, pain, sensation, active and passive range of motion, how to do activities of daily living, and by prescribing a series of exercises (e.g. flexion and extension active motions in fingers) and specific splinting and also ergonomic reforms come into effect [2]. The purpose of splinting after the operation is to maximize the movement of extension on the fingers [1]. The splint used for postoperative DC is a Paddle splint [3]. This splint can be used in a variety of ways; palmar or dorsal, and static or dynamic, in which the static type is used in further treatment [4]. There are different opinions and results about the effect of splinting after Dupuytren's operation and the duration of the use of this method, the position of the wrist and fingers in terms of angle, and the amount of force that should be applied to the various joints.

Larson and Jerosch-Herold (2008) in a review article concluded that there was little evidence to support the impact of splinting after DC operation, and this limited evidence was also used to confirm the effect of static or dynamic splint on reducing the rate of expansion defects in severe flexion contracture (equal to and greater than 40 degrees); proximal interphalangeal joints have contradictory meanings. This limited evidence to support the static or dynamic splinting effect on reducing extreme flexion contracture defects in the extension (equal to or greater than 40 degrees) of proximal interphalangeal joints were contradictory meanings [5]. 
Another study was conducted by Jerosch-Herold et al. in 2008 to investigate the effect of splinting after DC operation. The result of this study showed that more studies were required to confirm the clinical effect of night splinting after fasciotomy or derma fasciotomy operation of DC [6]. Considering the fact that most studies were done about the effect of splinting after DC operation, further studies are required in this regard, and regarding the important role of hands in performing various types of activities of daily living and the consequences of injuries, there is a need for more research in this regard. Therefore, this review study aimed at investigating the effect of splinting after DC operation.

\section{Methods}

To carry out this research, a kind of systematic evidencebased review process (Duffy 2005) was used [7].

\section{Search strategy}

For data gathering, all Persian articles, which examined the effect of various splinting after DC operation, as well as related published foreign articles between 1990 and January of 2019, were used. The following sources were: 1) Electronic databases, including Medlin, PubMed, Google Scholar, CINAHL, Ovid, Cochrane, ProQuest, Up to Date, Web of Science, OT search, OT direct, OT BibSys, Pedro, SID, Magiran, Iran Medex, Madlib, and Iran doc, 2) Iranian and foreign famous journals, including Iranian Rehabilitation Journal (IRJ), Iranian Journal of Child Neurology (IJCN), Archive Physical Medicine and Rehabilitation (APMR), Developmental Medicine, American Journal of Occupational Therapy (AJOT), Koomesh, Archives of bone \& joint operation, Rehabilitation journal, Journal of Medical Council of Iran, Journal of Research in Rehabilitation Science, and Hand Therapy Journal. The keywords used individually or in combination according to the MeSH were as follow: "Dupuytren's contracture", "splinting", "post-operative splinting", "systematic review", "management for Dupuytren's contracture", "hand therapy", "rehabilitation", and "occupational therapy".

\section{Inclusion and exclusion criteria}

The inclusion criteria were research studies on the effect of static, dynamics, and day and night splints on the pain reduction of postoperative DC operation. All retrospective and prospective papers, experimental and quasi-experimental studies, or observational studies that reviewed the effects of night/day, dynamic/static splints at least 10 to 14 days after the operation and up to 2 months after the operation have entered this study. Articles that studied the effects of splinting on problems other than DC were removed from the study. The articles included in this study were in I, II, and III levels of evidence-based on the evidence-based model $[8,9]$ :

Level I-randomized controlled trials (RCTs), systematic reviews, and meta-analyses

Level II-non-randomized studies (e.g., cohort, case-control) and two groups

Level III—one group, non-randomized studies (e.g., pretest-posttest)

Level IV-descriptive studies that include analysis of outcomes (e.g., single-subject design, case series)

Level V-case reports and expert opinion that include narrative literature reviews and consensus statements

All of the articles that were theses, presentations, and conferences that were in the levels IV and V evidence were excluded from this review (Table 1).

Table 1. Inclusion and exclusion critera

\begin{tabular}{|c|c|}
\hline Inclusion Criteria & Exclusion Criteria \\
\hline Iranian and English article about the DC & Articles that were found other than Persian or English. \\
\hline Related articles between 1990 and January 2019. & Articles that had been done before 1990 . \\
\hline Articles related to the effects of splinting on postoperative DC. & $\begin{array}{l}\text { Articles related to the effects of splinting on other disorders and } \\
\text { contractures. }\end{array}$ \\
\hline The availability of full-text articles or abstracts. & Articles related to the effect of splinting before the DC operation. \\
\hline $\begin{array}{l}\text { Retrospective and prospective papers, experimental and quasi- } \\
\text { experimental studies, or observational studies that reviewed the } \\
\text { effects of night/day, dynamic/static splints at least } 10 \text { to } 14 \text { days } \\
\text { after the operation and up to } 2 \text { months after the operation. }\end{array}$ & $\begin{array}{l}\text { Theses, presentations, conferences, and articles were in the level } \\
\text { IV and V evidence. }\end{array}$ \\
\hline
\end{tabular}




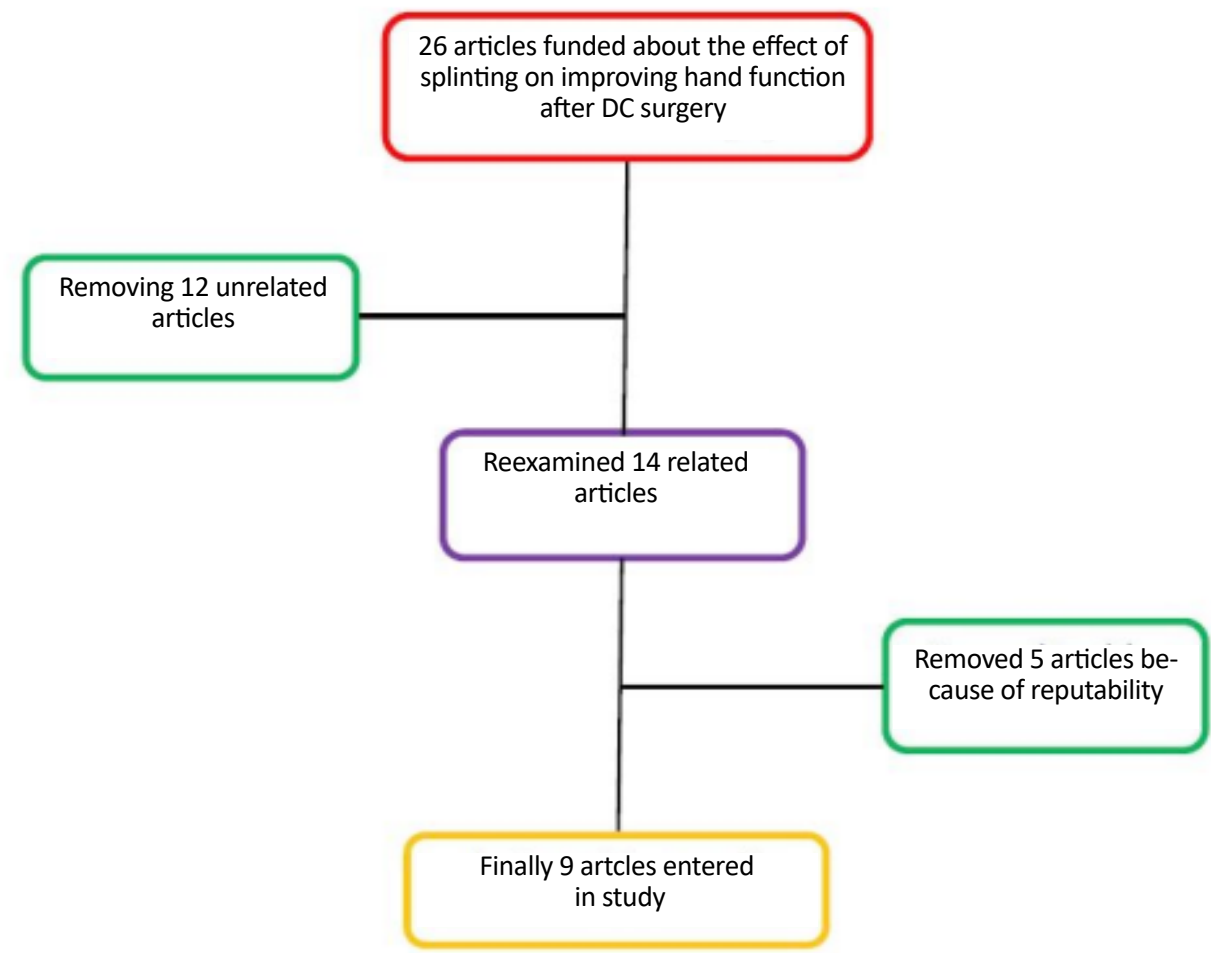

Figure 1. Flowchart of study selection

Iranian Rehabilitation Dournal

\section{Results}

A total of 26 articles on the effect of splinting on improving hand function after DC operation with 22 articles with fulltext and 4 abstracts were found. After reviewing the abstracts of the articles and the text of the articles, 12 articles related to the effects of splinting after the DC operation, which included the inclusion criteria were selected. After deep reviewing of those 12 articles, 3 of them were removed because of repeatability and, finally, 9 articles ( 8 were at the level of I evidence [6 RCTs and 2 reviews] based on level and 1 was at level III) entered this study (Figure 1).

The methodological quality of the included studies

Table 2 presents the results of the methodological quality assessment of the 7 included RCTs studies. Four of the 6 RCTs included in our review were of high quality (67\%). Another 2 RCTs scored $40 \%$ to $50 \%$ of the total score $(33 \%)$. Based on the methodological quality of the assessment, if the quality of studies is $>50 \%$, it is high quality, if it is $50>$ quality $>30$, the quality is moderate, and if it is $<30$, it is low quality [10].

The results of the review of the articles led to the classification of the study into 6 categories, including 1) The effect of static splint after DC operation, 2) The effect of dynamic splint after DC operation, 3) The effect of day splint after DC operation, 4) The effect of night splint after DC operation, 5) The effect of time duration of splinting after DC operation, and 6) The effect of the prescribed time of splinting after DC operation. Table 3 presents the results of the review articles.

\section{Discussion}

Since DC is considered as a progressive disorder, there is no definitive treatment for this disorder. Nevertheless, in the middle to severe phases, the first line is fasciotomy operation. After the operation and also in the first phases of the disease, the best and most effective intervention is rehabilitation, which includes all hand therapy modalities and splinting. Dynamic and static splints are among the most commonly used splints in these patients and can be used either overnight or throughout the day [11]. According to the study, it was found that the best and most useful splints among patients with DC are the static splints. However, in a study by Rives et al., the long-term use of dynamic splints could improve the extension movement of the proximal interphalangeal joints of fingers [12].

Regarding the splint administration time, there was no definitive conclusion. In the study of Jerosch-Herold et al., splint administration was reported 10 to 14 days postoperatively with lower pressure and more effective than late injection with high force splint [6]. In connection with the use of splint during the night or day, most 
Table 2. Methodological quality scores of the included RCTs

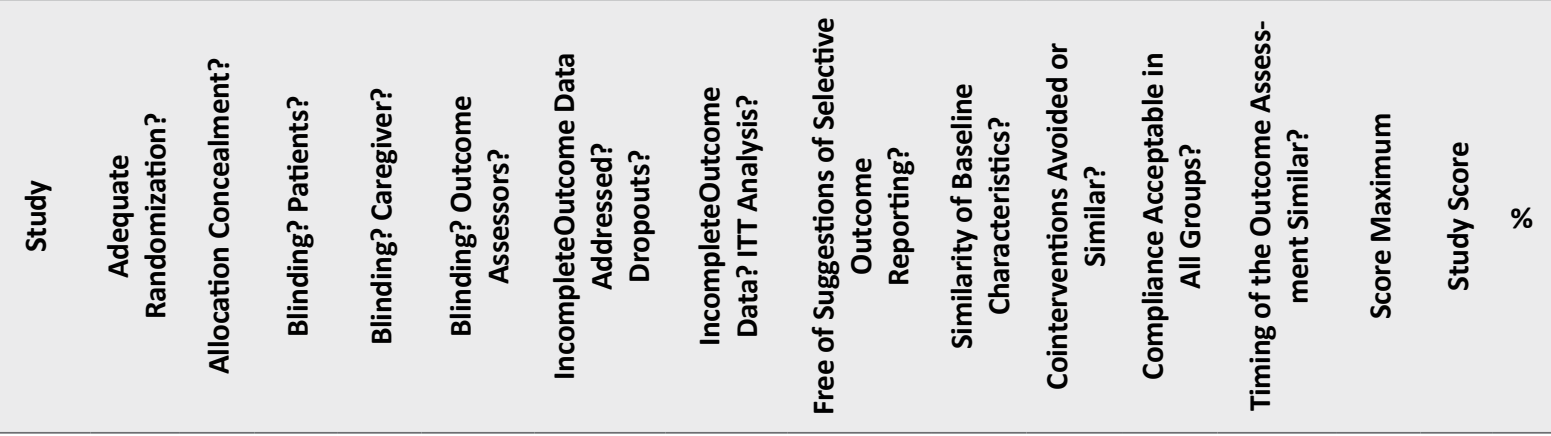

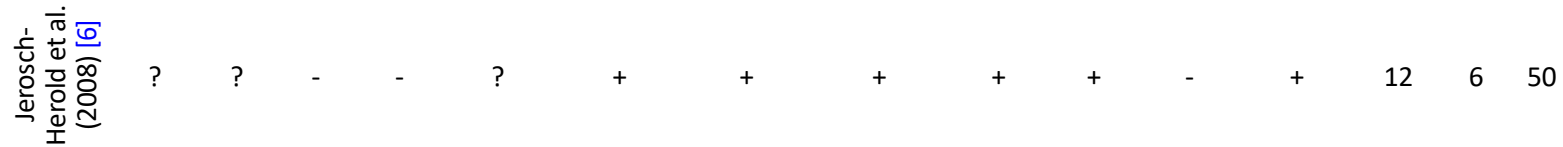

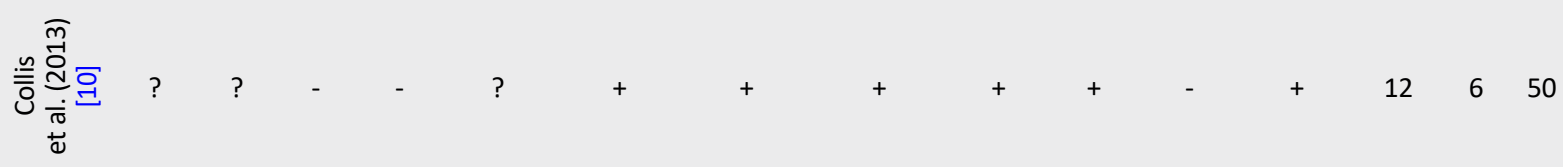

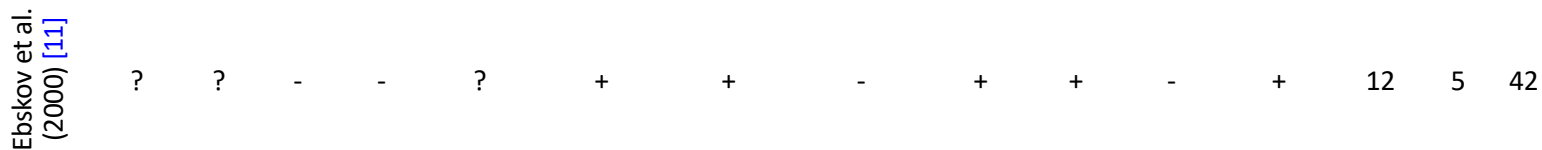
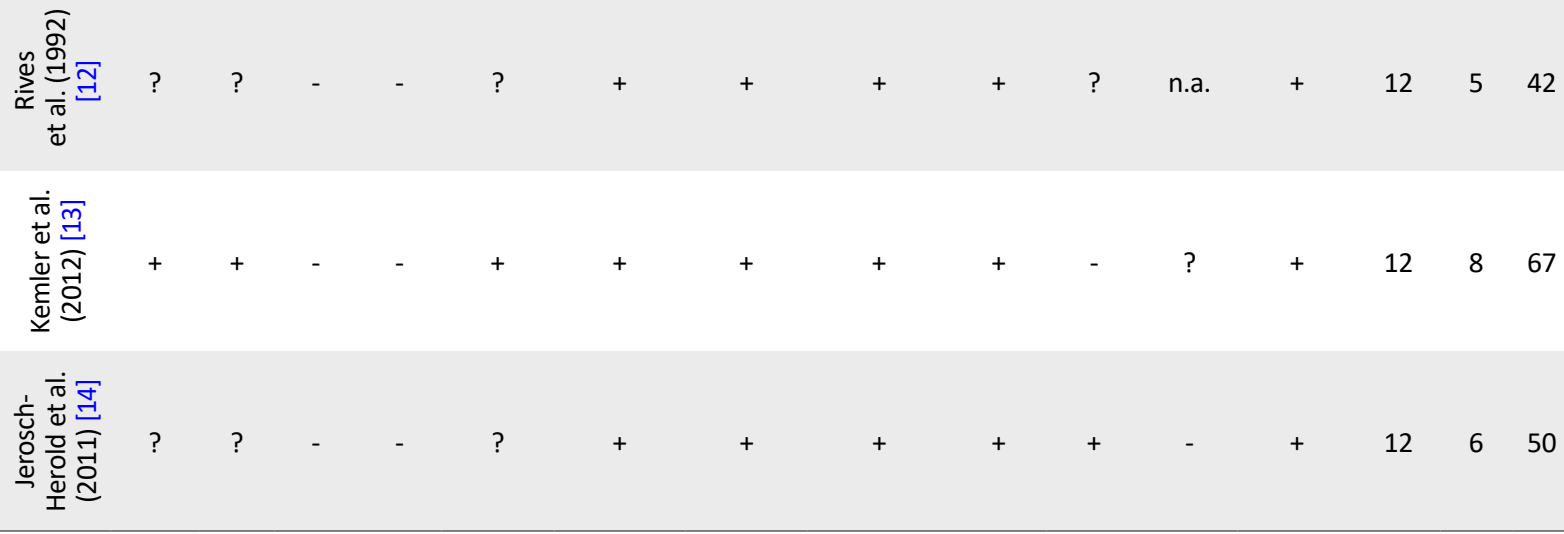

Iranian Rehabilitation Journa

+: yes; -: no; ?: unsure; ITT: Intention To Treat; n.a: not applicable (in a 1-time intervention, such as operation, hand therapy, compliance is not an issue).

studies also emphasized the ineffectiveness of nighttime splinting and suggested the use of splint during the day, although unpleasant for the individuals $[5,6$, 13-16]. Most studies about the DC suggested that the rehabilitation (exercise) and splinting each alone have been ineffective in reducing the contracture of these individuals; they also concluded that occasional and irregular use of splint also has no effect on pain relief and the reduction of contracture $[11,13]$.

\section{Conclusion}

The most effective way for the treatment of DC is to use a splint (preferably static) and hand therapy (exercise) together. In addition, after the operation, hand rehabilitation and splint with low pressure should be administered as soon as possible. The pressure and force of splint will be gradually increased, and the splint should be used at least for 3 months too.

The lack of access to free hand therapy journals is one of the limitations of this study. Also, a small number of papers in the impact analysis of splint, especially day/night and static/ 
Table 3. The results of the review articles

\begin{tabular}{|c|c|c|c|c|c|c|c|}
\hline & 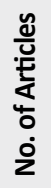 & 高 & 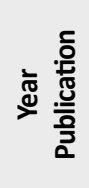 & 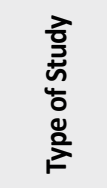 & 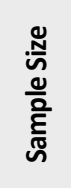 & 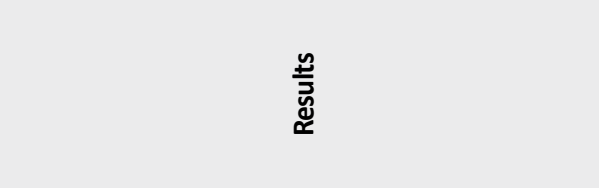 & 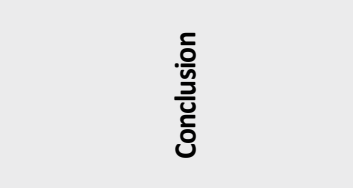 \\
\hline \multirow{4}{*}{ 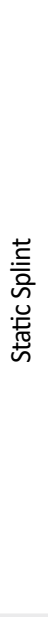 } & \multirow{4}{*}{5} & 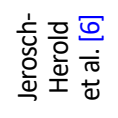 & 2008 & RCT & 15 & $\begin{array}{l}\text { The use of static splints has been effective in improv- } \\
\text { ing the range of motion and performance of their } \\
\text { hands. }\end{array}$ & \multirow{4}{*}{$\begin{array}{l}\text { The static splint in people with } \\
\text { severe DC and its long-term use } \\
\text { can be effective in improv- } \\
\text { ing the performance of these } \\
\text { individuals. There are not any } \\
\text { differences between using } \\
\text { splints and hand therapy with } \\
\text { hand therapy alone but using } \\
\text { splint maintains this improve- } \\
\text { ment longer than hand therapy } \\
\text { alone. }\end{array}$} \\
\hline & & 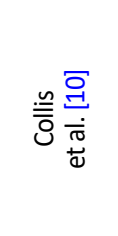 & 2013 & RCT & 56 & $\begin{array}{l}\text { There were no statistically significant differences } \\
\text { between the no-static orthosis and static orthosis } \\
\text { groups for total active extension or for any of the } \\
\text { secondary outcomes. Between the first postoperative } \\
\text { measure and } 3 \text { months after the operation, } 62 \% \text { of } \\
\text { little fingers had maintained or improved total active } \\
\text { extension. }\end{array}$ & \\
\hline & & 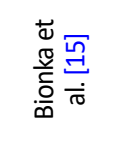 & 2018 & Review & 290 & $\begin{array}{l}\text { This study concluded that splinting (static) and hand } \\
\text { therapy had the same effect on DC patients and } \\
\text { these interventions can be used after the operation } \\
\text { and none is overcome to another. }\end{array}$ & \\
\hline & & 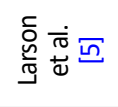 & 2008 & Review & 28 & $\begin{array}{l}\text { The use of static splint in the postoperative phase } \\
\text { in people with severe DC increases the extension of } \\
\text { their fingers and is more effective in long-term use. }\end{array}$ & \\
\hline \multirow{3}{*}{ 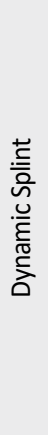 } & \multirow{3}{*}{4} & $\begin{array}{l}\bar{\pi} \\
\stackrel{ \pm}{0} F \\
\frac{\tilde{\partial}}{\tilde{u}} \\
\bar{u}\end{array}$ & 2000 & RCT & 15 & $\begin{array}{l}\text { Usage and dis usage of The dynamic splinting have no } \\
\text { affected on hand function and even on the postoper- } \\
\text { ative restoration of the contracture. It is even better } \\
\text { not to use splint after the operation to have a better } \\
\text { and more comfortable manipulation of the fingers. }\end{array}$ & \multirow{3}{*}{$\begin{array}{l}\text { The use of dynamic splinting if } \\
\text { combined with other rehabilita- } \\
\text { tion treatments can help to } \\
\text { improve the performance of } \\
\text { the hand. }\end{array}$} \\
\hline & & 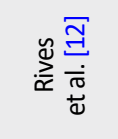 & 1992 & RCT & 27 & $\begin{array}{l}\text { The use of dynamic splinting, if used simultaneously } \\
\text { with other rehabilitation interventions, has more } \\
\text { pronounced effectiveness with DC, especially in PIP } \\
\text { joints. }\end{array}$ & \\
\hline & & 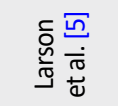 & 2008 & Review & 28 & $\begin{array}{l}\text { The use of dynamic splint in the postoperative phase } \\
\text { in people with severe DC increases the extension of } \\
\text { their fingers and is more effective in long-term use. }\end{array}$ & \\
\hline 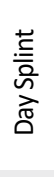 & 1 & 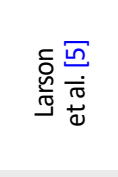 & 2008 & Review & 28 & $\begin{array}{l}\text { In this paper, there was no difference between the } \\
\text { use of day splint and night, and the difference was } \\
\text { more in the static or dynamic. }\end{array}$ & $\begin{array}{l}\text { There is no significant differ- } \\
\text { ence in the use of the day } \\
\text { splint, night splint, and only the } \\
\text { most important point is to use } \\
\text { splinters i n postoperative DC. }\end{array}$ \\
\hline \multirow{5}{*}{ 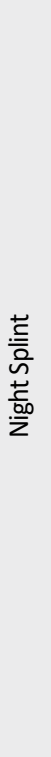 } & \multirow{5}{*}{6} & 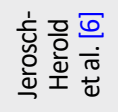 & 2008 & RCT & 15 & $\begin{array}{l}\text { The use of night static splints has been effective in } \\
\text { improving the range of motion and performance of } \\
\text { their hands. }\end{array}$ & \multirow{5}{*}{$\begin{array}{l}\text { The use of night splint to } \\
\text { reduce the contracture, reduce } \\
\text { pain and increase strength, and } \\
\text { increase the range of motion of } \\
\text { fingers is not very impressive. } \\
\text { However, there is a need for } \\
\text { more and more specific studies } \\
\text { among people with DC. }\end{array}$} \\
\hline & & 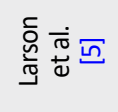 & 2008 & Review & 28 & $\begin{array}{l}\text { In this paper, there was no difference between the } \\
\text { use of day splint and night, and the difference was } \\
\text { more in the static or dynamic. }\end{array}$ & \\
\hline & & 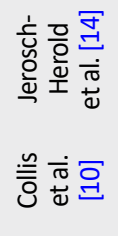 & 2013 & RCT & 148 & $\begin{array}{l}\text { The use of night static splints has been effective in } \\
\text { improving the range of motion, satisfaction, and } \\
\text { performance of participants. } \\
\text { The participants were instructed to apply the orthosis } \\
\text { overnight and remove it during the daytime. }\end{array}$ & \\
\hline & & 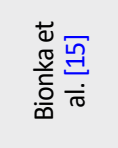 & 2018 & Review & 290 & $\begin{array}{l}\text { This study concluded that splinting and hand therapy } \\
\text { had the same effect on DC patients and these inter- } \\
\text { ventions can be used after the operation and none is } \\
\text { overcome to another. }\end{array}$ & \\
\hline & & 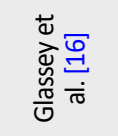 & 2001 & $\begin{array}{c}\text { Pre/ } \\
\text { post- } \\
\text { test }\end{array}$ & 31 & $\begin{array}{l}\text { It was suggested in this article that the use of night } \\
\text { splints has no effect on increasing the extension of } \\
\text { fingers, reducing pain, increasing strength, and reduc- } \\
\text { ing flexor deformity in the fingers. }\end{array}$ & \\
\hline
\end{tabular}




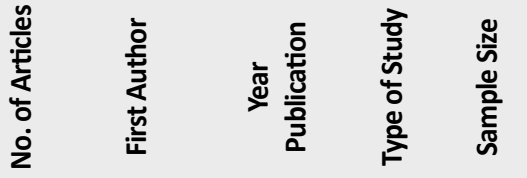 ำ

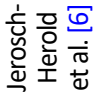 $2008 \quad \mathrm{RCT} \quad 15$

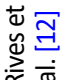 \\ 1992 \\ $\mathrm{RCT}$ \\ 27

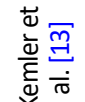 \\ RCT \\ 54}

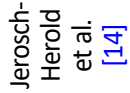

2011

$\mathrm{RC}$

148

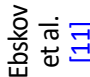

2000

$\mathrm{RC}$

15

릉

RCT

56

2018

Review

290

음

든

Review

In this study, the splint was used in at least 6 weeks (1.5 months).

In this study, the splint was used for 1 year (12 months) by postoperative DC. Of course, evaluations are after 3 months, 6 months, and finally 12 months.

In this study, individuals used a dynamic splint for 9 months after DC operation.

In this study, the splint was used for 3 months after the DC operation.

The 3 studies that were included in this study used splint between 3 and 12 months. depends on the patient's acceptance and the therapist's opinion. Long-term use of at least 3 months and the use of static splinting can be effective.

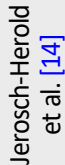

2011

RCT

148

In this study, night static splint was prescribed to patients immediately after the operation. Patients used a night static splint for 3 weeks that did not enter the tension and compression to the wound. After 3 weeks, and since the wound healing was because of operation, another static splint was prescribed to the patients.

The time of splint administration is because of a number of factors, including the type of operation, the severity of contracture, the number of times a person has undergone the operation, and the decision of the therapist. However, faster administration of the splint after the operation can have a better effect.
苍㔯
Review
290
In this study, the splint was used for 3 months after the DC operation.
든도 
dynamic, are among the other limitations of this study. It is suggested that the hand-therapists and occupational therapists examine the impact of splinting and different kinds of splints types on DC.

\section{Ethical Considerations}

\section{Compliance with ethical guidelines}

The Ethics Committee of Iran University of Medical Sciences approved this study (Code: IR.IUMS.REC. 28930). All participants signed informed consent to participate in the study. A code number was placed on each participant's name to provide confidentiality.

Funding

This research was supported by Iran University of Medical Sciences (Grant No. 95-02-32-28930).

\section{Authors' contributions}

Conceptualization: Akram Azad, Ghazale Golabi; Methodology: Akram Azad, Malek Amini; Investigation: Gazaleh Golabi, Marzieh Pashmdarfard, Malek Amini; Writing Original Draft: Akram Azad, Marzieh Pashmdarfard; Writing - Review \& Editing: Akram Azad, Marzieh Pashmdarfard; Supervision: Akram Azad.

\section{Conflict of interest}

The authors declared no conflict of interest.

\section{Acknowledgments}

The Authors would like to thank Iran University of Medical Sciences for their financial support of this study.

\section{References}

[1] Saunders RJ, Astifidis RP. McClinton MA. Hand and upper extremity rehabilition: A pracice guide [A Azad, L Lajevardi Persian Trans.], 2nd ed. Tehran: Hasti-Setaish; 2018.

[2] Judith M, Conolly B. The Hand: Fundamental of Therapy [A Azad, Persian Trans.]. Tehran: Nor-e-Danesh; 2004.

[3] Jacons A, Austin N. Splinting the hand and upper extremity: principles and process. Philadelphia: Lippincott Williams \& Wilkins; 2003.

[4] Moosavi S, Azad A, Amini M, Edrisy M, Taghizadeh G. Effect of paddle static splint on muscle tone, range of motion, and dexterity of upper-extremity in children with spas- tic hemiplegia. Journal of Rehabilitation Medicine. 2016; 5(1):174-82.

[5] Larson D, Jerosh-Herold C. Clinical effectiveness of post-operative splinting after surgery release of Dupuytren's contracture: A systematic review. BMC Musculoskeletal Disorders. 2008; 104(9):1-10. [DOI:10.1186/1471-2474-9-104] [PMID] [PMCID]

[6] Jerosh-Herold C, Spepstone L, Chojnowski A, Larson D. Splinting after contracture release for dupuytren's contracture: Protocol of a pragmatic, multi-centre, randomized. BMC Musculoskeletal Disorders. 2008; 62(9):1-5. [DOI:10.1186/1471-2474-9-62] [PMID] [PMCID]

[7] Law M, Mac-Dermid J. Evidence-based rehabilitation: A guide to practice. Thorofare: SLACK; 2005.

[8] Lieberman D, Scheer J. AOTA's evidence-based literature review project: An overview. American Journal of Occupational Therapy. 2002; 56:344-9. [DOI:10.5014/ajot.56.3.344] [PMID]

[9] Sackett DL, Rosenberg WM, Gray JA, Haynes RB, Richardson WS. Evidence based medicine: What it is and what it isn't BMJ. 1996; 312 (7023):71-2. [DOI:10.1136/bmj.312.7023.71] [PMID] [PMCID]

[10] Collis J, Collocott S, Hing W, Kelly E. The effect of night extension orthoses following surgical release of Dupuytren contracture: A single-center, randomized, controlled trial Journal Hand Surgery American. 2013; 38(7):1285-94.e2 [DOI:10.1016/j.jhsa.2013.04.012] [PMID]

[11] Ebskov LB, Boeckstyns ME, Sorensen AI, Soe-Nielsen N Result after surgery for severe Dupuytren's contracture: Does a dynamic extension splint influence outcome? Scand Journal Plast Reconstr Surgery Hand Surgery. 2000; 34(2):155-60. [DOI:10.1080/02844310050160024] [PMID]

[12] Rives K, Gelberman R, Smith B, Carney K. Severe contractures of the proximal interphalangeal joint in Dupuytren's disease: Results of a prospective trial of operative correction and dynamic extension splinting. Journal Hand Surgery American. 1992; 17(6):1153-9. [DOI:10.1016/S0363-5023(09)91084-X] [PMID]

[13] Kemler MA, Houpt P, van der Horst CM. A pilot study assessing the effectiveness of post-operative splinting after limited fasciectomy for Dupuytren's disease. Journal Hand Surgery. 2012; 37(8):733-7. [DOI:10.1177/1753193412437631] [PMID]

[14] Jerosch-Herold C, Shepstone L, Choinowski AJ, Larson D BE, Vaughan SP. Night-time splinting after Fasciectomy or dermo-fasciectomy for Dupuytren's contracture: A pragmatic, multi-centre, randomized controlled trial. BMC Musculoskeletal Disorders. 2011; 136(12):1-9. [DOI:10.1186/1471-247412-136] [PMID] [PMCID]

[15] Huisstede BM, Gladdines S, Randsdorp MS, Koes BW Effectiveness of conservative, surgical, and postsurgical interventions for trigger finger, dupuytren disease, and De-quervain disease: A systematic review. Archives of Physical Medicine and Rehabilitation. 2018; 99(8):1635-49. [DOI:10.1016/j.apmr.2017.07.014] [PMID]

[16] Glassey N. A study of the effect of night extension splintage on post-fasciectomy Dupuytren's patients. British Journal Hand Therapy. 2001; 6(3):89-94. [DOI:10.1177/175899830 701200303 